\title{
Impacts of Land Cover Change on the Near-Surface Temperature in the North China Plain
}

\author{
Ruijie Qu, ${ }^{1,2}$ Xiaolin Cui, ${ }^{1}$ Haiming Yan, ${ }^{3}$ Enjun $\mathrm{Ma},{ }^{4}$ and Jinyan $\mathrm{Zhan}^{3}$ \\ ${ }^{1}$ College of Geomatics, Xian University of Science and Technology, No. 58 Yanta Road, Xi'an 710054, China \\ ${ }^{2}$ Center for Chinese Agricultural Policy, Chinese Academy of Sciences, No. 11A Datun Road, Anwai, Beijing 100101, China \\ ${ }^{3}$ State Key Laboratory of Water Environment Simulation, School of Environment, Beijing Normal University, Beijing 100875, China \\ ${ }^{4}$ School of Mathematics and Physics, China University of Geosciences, No. 388 Lumo Road, Wuhan 430074, China
}

Correspondence should be addressed to Jinyan Zhan; zhanjy@bnu.edu.cn

Received 11 June 2013; Accepted 30 July 2013

Academic Editor: Xiangzheng Deng

Copyright (c) 2013 Ruijie Qu et al. This is an open access article distributed under the Creative Commons Attribution License, which permits unrestricted use, distribution, and reproduction in any medium, provided the original work is properly cited.

\begin{abstract}
This study first tested and verified the ability of the Weather Research and Forecasting (WRF) model to simulate the near-surface temperature in the North China Plain. Then the static land cover data in the WRF were replaced, and thereafter the modified WRF model was used to explore the impacts of land cover change on the near-surface temperature in the North China Plain in year 1992 and year 2005. The results indicated that the land cover change in the North China Plain, which was characterized by the regional urbanization, had led to significant changes in the near-surface temperature, increasing the regional near-surface temperature by $0.03^{\circ} \mathrm{C} /$ year on average. The spatial pattern of the climate change basically corresponded to that of the land cover change; for example, the temperature increased most significantly in the regions mainly consisting of cities and built-up area. Besides, there were some variations in the degree and range of influence of the land cover change on the temperature among seasons. The result can provide important theoretical support for the adaptation to climate change, scientific land cover change management, and land use planning.
\end{abstract}

\section{Introduction}

More and more attention has been paid to the influence of human activities on the climate system in recent years as great progress has been made in the researches on the global climate system and environmental change. IPCC AR4 pointed out that the human activities may account for $90 \%$ of the reasons for the global warming. There is very complex influence of human activities on the climate, with the land use/cover change (LUCC) being considered as the major influencing factor in the climate system [1]. The LUCC influences the climate system at various temporal and spatial scales, and the land use change has contributed to $1 / 3$ of the increase in global $\mathrm{CO}_{2}$ emission since the 1750 s. Besides, a lot of observations and simulation experiments also indicate that the LUCC at various spatial scales has been one of the most important approaches through which the human activities exert influence on the climate [2-4]. The LUCC mainly influences the climate at the local, regional, and global scales by changing the land surface characteristics, altering the exchange of energy, water, and other materials between the land surface and the atmosphere and influencing other biogeochemical processes. There is great variation in the biogeochemical mechanism through which the LUCC influences the climate in different regions; the climate change caused by LUCC is mainly through the land-atmosphere interaction and is closely related to the regional climate and environmental background, terrain, vegetation, and so forth. Therefore, it is of great importance to study the influence of LUCC on the regional climate.

The North China Plain has been selected as the study area in this study. First, it has long been one of the most densely populated regions in China; the current regional city density is still very high and the industries and agriculture are well developed. The rapid economic development and increasing 


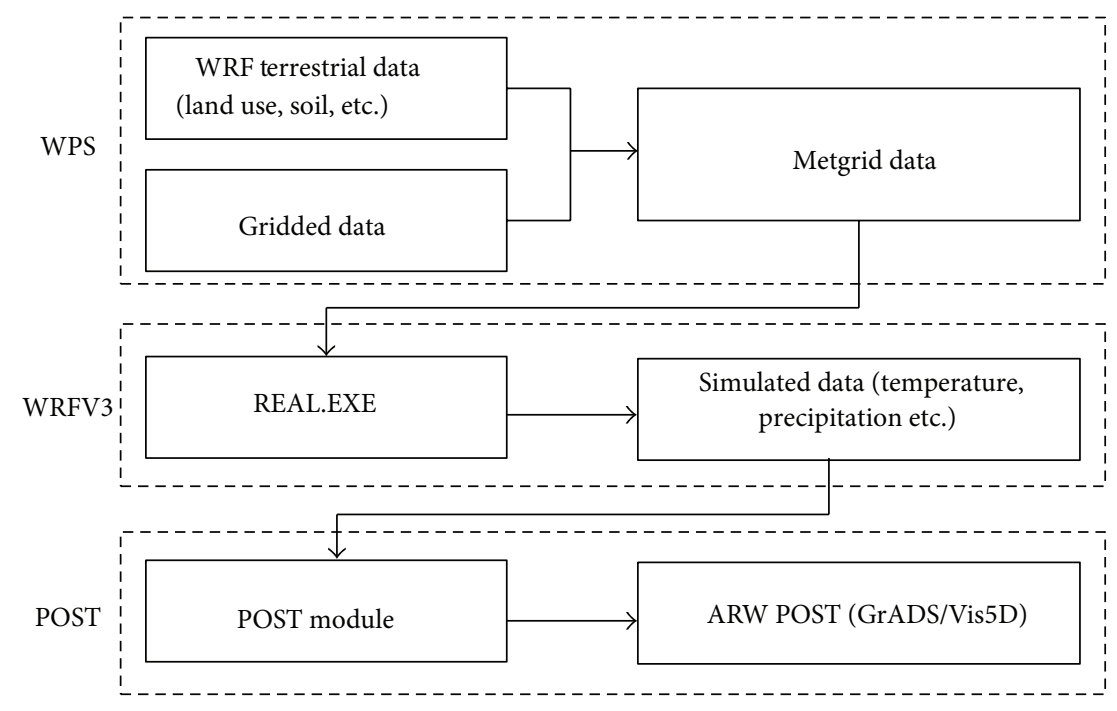

FIGURE 1: WRF flow chart.

population have led to very dramatic land cover change in this region, and the human disturbance to the environment is especially significant, which greatly influences the sustainable development of the whole China. Second, the North China Plain is a typical area of the monsoon climate as well as the transient region between the humid and subhumid region and the arid and semiarid region. On the one hand, the plain agriculture can be sustained for a long time due the local climatic conditions. On the other hand, the local climatic conditions also lead to more frequent droughts, make the agricultural production extremely unstable, and consequently may lead to greater economic loss and more extensive social influence. Therefore, it is of great importance to study the influence of LUCC on the climate in the North China Plain.

This study first tested the ability of the Weather Research and Forecasting (WRF) model to simulate the change of the near-surface temperature in the North China Plain, based on which the static land cover data in the WRF were then replaced. Thereafter the modified WRF was used to study the influence of the land cover change on the near-surface temperature in the North China Plain in year 1992 and year 2005. The result can contribute to better understanding of the influencing factors of the climate in the North China Plain so as to minimize the negative influence and maximize the positive influence on the regional climate, which is helpful to the scientific regional land use planning and management in China in the future.

\section{Model Introduction and Experiment Design}

2.1. Model Introduction. With the development of the atmospheric models and land surface process models, the numerical simulation has become a widely used approach to study the influence of climate on vegetation. The regional climate model used in this study, WRF model, has been widely used in the global climate and achieved good simulation result [5-9]. The WRF model is a next-generation mesoscale numerical weather prediction system designed to serve both atmospheric research and operational forecasting needs. The ARW-WRF (Edition 3.3) has been used in this study.

ARW-WRF includes three parts: WRF Preprocessing System (WPS), WRFV3, and POST (Figure 1). The WPS program is used primarily for real-data simulations. Its functions include (1) defining simulation domains, (2) interpolating terrestrial data (such as terrain, land use, and soil types) to the simulation domain, and (3) degribbing and interpolating meteorological data from another model to this simulation domain. Its main features include (1) GRIB 1/2 meteorological data from various centers around the world; (2) USGS 24 category land datasets; (3) map projections for polar stereographic, Lambert Conformal, Mercator, and latitudelongitude; (4) nesting; (5) user-interfaces to input other static data as well as met data. WRFV3 runs and exports simulated data, including temperature, precipitation, and so forth. POST part converts the results and makes the outputs visualized.

ARW offers multiple physical parameterization schemes that can be combined in any way. The options typically range from simple and efficient to sophisticated and more computationally costly and from newly developed schemes to well-tried schemes such as those in current operational models. Table 1 lists some schemes.

2.2. Experiment Design. The location and size of the simulation area have great influence on the simulation result $[10,11]$. The center line of the simulation area was set to be $36^{\circ} \mathrm{N}$ and $117^{\circ} \mathrm{E}$ in this study. The Lambert projection was used, with the two standard parallels being $26^{\circ} \mathrm{N}$ and $46^{\circ} \mathrm{N}$, respectively. The spatial resolution was set to be $20 \mathrm{~km}$, and there were 112 grid points in the east-west direction and 97 grid points in the north-south direction in the whole simulation area.

The lateral boundary forcing data came from the National Centers for Environmental Prediction (NCEP)/FNL dataset 
TABLE 1: Physical parameterization schemes.

\begin{tabular}{|c|c|}
\hline Physical parameters & Schemes \\
\hline Microphysics & $\begin{array}{l}\text { Kessler, Lin et al., WRF } \\
\text { Single-Moment 3-class }\end{array}$ \\
\hline $\begin{array}{l}\text { Cumulus } \\
\text { parameterization }\end{array}$ & $\begin{array}{l}\text { Kain-Fritsch, Grell-Devenyi ensemble } \\
\text { scheme, Betts-Miller-Janjic }\end{array}$ \\
\hline Shortwave radiation & $\begin{array}{l}\text { Dudhia (MM5), CAM scheme, } \\
\text { Goddard }\end{array}$ \\
\hline Longwave radiation & RRTM, CAM, GFDL \\
\hline Planetary boundary layer & MRF, MYJ, YSU \\
\hline Land surface & $\begin{array}{l}\text { 5-layer thermal diffusion, Noah Land } \\
\text { Surface Model, RUC Land Surface } \\
\text { Model }\end{array}$ \\
\hline
\end{tabular}

and were updated every 6 hours. This dataset has the spatial resolution of $1^{\circ} \times 1^{\circ}$ and the vertical height of 27 layers, and it has been established and updated since July of 1999 with the data assimilation of almost all kinds of observation data (e.g., remote sensing data and ground-based observation data). In comparison to the datasets of NCEP I, NCEP II, and EAR40, the NCEP/FNL dataset has higher accuracy and spatial resolution, and it includes more kinds of environmental variables.

In the parameterization scheme of physical processes in the model, the cumulus parameterization scheme adopted the Grell-Devenyi ensemble scheme, the boundary layer process scheme was YSU, and the shortwave radiation scheme was the CAM scheme, while the land surface process scheme was Noah Land Surface Model. The boundary buffer was set to be 4 layers of grid points, and the boundary conditions adopted the relaxation scheme. The time interval of the model integration was set to be 5 minutes, and that of the radiation process and cumulus convection was 30 minutes and 5 minutes, respectively. There were 27 layers in the vertical direction and the atmospheric pressure at the top layer was $50 \mathrm{hPa}$.

The test scheme in this study is designed as follows (Table 2). In order to analyze the impact of land cover change on climate and reduce data errors, the land cover data used in this study were extracted from the Chinese subset of the Global Land Cover Characteristics database which was developed based on the AVHRR data with the support of IGBP-DIS in 1992 and the China subset of the MODIS land cover data product in 2005. The two datasets both adopt the IGBP classification and the time span is relatively large. The land cover dataset of 1992 is downloaded from land cover products of China on the website of Cold and Arid Regions Science Data Center. And the dataset of 2005 is extracted from the Chinese subset of the MODIS land cover data product in 2005 which is downloaded from $\mathrm{ftp} / /$ e4ft101.cr.usgs.gov/MOTA/. There were two sets of tests; one was the control test and the other was the sensitivity test, the difference between which was related to the land cover types of the underlying surface. The land cover data of 1992 was used in the control test and that of 2005 was used in the sensitivity test. In addition to replacing land cover data, the other input parameters and the parameterization scheme
TABLE 2: Schemes of the simulation test.

\begin{tabular}{lcc}
\hline Test & Test period & $\begin{array}{c}\text { Land cover data used in } \\
\text { the WRF model }\end{array}$ \\
\hline Control test & $2005.10-2007.12$ & Land cover data of 1992 \\
Sensitivity test & $2005.10-2007.12$ & Land cover data of 2005 \\
\hline
\end{tabular}

of the physical process are the same in the two tests. They were both implemented with the climate forcing data between October of 2005 and December of 2007.

\section{Data Processingb}

3.1. Processing of Land Cover Data. It is necessary to reclassify the land cover data with the USGS land cover classification which includes 24 land cover and land use types and set the spatial resolution to be $20 \mathrm{~km}$ according to the requirement of the WRF model. Therefore, the land cover data of the IGBP land cover classification were first reclassified with the USGS land cover classification system, and then the spatial resolution of the data was converted from $1 \mathrm{~km}$ to $20 \mathrm{~km}$. The two datasets both have the spatial resolution of $1 \mathrm{~km}$ and adopt the IGBP classification. On the basis of the data of the IGBP land cover classification, we formulated the transformation method from the IGBP land cover classification to the USGS land cover classification (Table 3) and established the land use and land cover dataset of the USGS classification of the North China Plain.

The LUCC data were further upscaled on the basis of the data mentioned above so as to embed the high resolution underlying surface data into the large-scale climate model. In this study, the $1 \mathrm{~km}$ resolution land cover and land use data of USGS classification were upscaled into the $20 \mathrm{~km}$ resolution data with the resampling function of ArcGIS. Besides, the three kinds of data were integrated in a system of 7 land cover types, and their area consistency and spatial consistency were analyzed so as to check the change of the classification accuracy of the land cover and land use data before and after the reclassification and upscaling. The total area difference between the land cover data that were reclassified and upscaled and the initial data was presented in Table 4. It indicated that there was no significant difference in the total area of each land cover type before and after reclassification and upscaling and the total area was consistent on the whole, indicating that the reclassification and upscaling were reasonable.

There was a high overall consistency between the $1 \mathrm{~km}$ resolution initial data of the IGBP classification and USGS classification in year 1992 and year 2005, except the slight difference in the total area of grassland, water bodies, and unused land. Besides, the $20 \mathrm{~km}$ resolution data of USGS classification differed from both of the other two kinds of land cover data. The result of the comparison between the initial data and the upscaled USGS data of year 1992 indicated the area of irrigated cropland and pasture, grassland, and water bodies decreased by $2.69 \%, 7.78 \%$, and $41.42 \%$, respectively, while the area of dryland cropland and pasture, deciduous broadleaf forest, urban and built-up land, and unused land 
TABLE 3: Remapping tables of land-cover and land-use classification.

\begin{tabular}{|c|c|c|c|c|}
\hline \multicolumn{2}{|c|}{ USGS land cover classification } & \multirow{2}{*}{$\begin{array}{c}\text { Correspondence } \\
14 \leftarrow 01\end{array}$} & \multicolumn{2}{|c|}{ IGBP land cover classification } \\
\hline 01 & Urban and built-up land & & 01 & Evergreen needle leaf \\
\hline 02 & Dryland cropland and pasture & $13 \leftarrow 02$ & 02 & Evergreen broadleaf \\
\hline 03 & Irrigated cropland and pasture & $12 \leftarrow 03$ & 03 & Deciduous needle leaf \\
\hline 04 & Mixed dryland/irrigated cropland and pasture & $11 \leftarrow 04$ & 04 & Deciduous broadleaf \\
\hline 05 & Cropland/grassland mosaic & $15 \leftarrow 05$ & 05 & Mixed forest \\
\hline 06 & Cropland/woodland mosaic & $08 \leftarrow 06$ & 06 & Closed shrublands \\
\hline 07 & Grassland & $09 \leftarrow 07$ & 07 & Open shrublands \\
\hline 08 & Shrubland & $08 \leftarrow 08$ & 08 & Woody savannas \\
\hline 09 & Mixed shrubland/grassland & $10 \leftarrow 09$ & 09 & Savannas \\
\hline 10 & Savanna & $07 \leftarrow 10$ & 10 & Grasslands \\
\hline 11 & Deciduous broadleaf forest & $17 \leftarrow 11$ & 11 & Permanent wetlands \\
\hline 12 & Deciduous needle leaf forest & $02 \leftarrow 12$ & 12 & Croplands \\
\hline 13 & Evergreen broadleaf forest & $01 \leftarrow 13$ & 13 & Urban and built-up \\
\hline 14 & Evergreen needle leaf forest & $05 \leftarrow 14$ & 14 & Cropland mosaics \\
\hline 15 & Mixed forest & $24 \leftarrow 15$ & 15 & Snow and ice \\
\hline 16 & Water bodies & $19 \leftarrow 16$ & 16 & Bare soil and rocks \\
\hline 17 & Herbaceous wetland & $16 \leftarrow 17$ & 17 & Water bodies \\
\hline 18 & Wooded wetland & & & \\
\hline 19 & Barren or sparsely vegetated & & & \\
\hline 20 & Herbaceous tundra & & & \\
\hline 21 & Wooded tundra & & & \\
\hline 22 & Mixed tundra & & & \\
\hline 23 & Bare ground tundra & & & \\
\hline 24 & Snow or ice & & & \\
\hline
\end{tabular}

TABLE 4: Comparison table of area percentage (\%) of each land-cover and land-use types among various kinds of classification systems.

\begin{tabular}{|c|c|c|c|c|c|c|}
\hline & \multicolumn{3}{|c|}{1992} & \multicolumn{3}{|c|}{2005} \\
\hline & IGBP $^{\mathrm{a}}$ & USGS $^{\mathrm{b}}$ & USGS $^{\mathrm{c}}$ & $\mathrm{IGBP}^{\mathrm{a}}$ & USGS $^{\mathrm{b}}$ & USGS $^{c}$ \\
\hline Irrigated cropland and pasture & 4.09 & 4.09 & 3.98 & 3.87 & 3.87 & 3.62 \\
\hline Dryland cropland and pasture & 66.11 & 66.11 & 66.52 & 64.52 & 64.52 & 65.43 \\
\hline Deciduous broadleaf forest & 6.48 & 6.48 & 6.51 & 6.55 & 6.55 & 6.06 \\
\hline Grassland & 7.07 & 7.37 & 6.52 & 6.79 & 6.78 & 7.96 \\
\hline Water bodies & 3.09 & 2.00 & 1.81 & 3.27 & 2.43 & 2.08 \\
\hline Urban and built-up land & 12.34 & 12.34 & 12.57 & 14.46 & 14.46 & 13.76 \\
\hline Unused land & 0.82 & 1.61 & 2.08 & 0.54 & 1.39 & 1.09 \\
\hline Total & 100 & 100 & 100 & 100 & 100 & 100 \\
\hline
\end{tabular}

Note: ${ }^{\mathrm{a}}$ represents the $1 \mathrm{~km}$ resolution data of IGBP classification, ${ }^{\mathrm{b}}$ represents the $1 \mathrm{~km}$ resolution data of USGS classification, and ${ }^{\mathrm{c}}$ represents the $20 \mathrm{~km}$ resolution data of USGS classification.

increased by $0.62 \%, 0.46 \%, 1.68 \%$, and $153.66 \%$, respectively. By contrast, that of year 2005 indicated the area of irrigated cropland and pasture, deciduous broadleaf forest, water bodies, and urban and built-up land decreased by $6.46 \%$, $7.43 \%, 36.35 \%$, and $4.87 \%$, respectively, while the area of dryland cropland and pasture, grassland, and unused land increased by $1.41 \%, 17.29 \%$, and $101.11 \%$, respectively.

The error matrix was used to assess the spatial consistency between the initial data and the data after reclassification in this study. The result indicated that the consistency of the land cover types except the unused land all exceeded 95\% (Table 5). The consistency of the urban and built-up land was the highest, reaching $99.25 \%$, followed by that of dryland cropland and pasture, which was $98.76 \%$. The overall consistency reached $96.84 \%$ and the Kappa coefficient was 0.95 , indicating the reclassification result had high classification accuracy.

3.2. Processing of Meteorological Data. The observation data, which were used to make a comparison with the simulated temperature in this study, came from the meteorological stations in the North China Plain. The meteorological data of the same period (January 2006-December 2007) of the 
TABLE 5: Error matrix of accuracy assessment for reclassifying land-cover and land-use types.

\begin{tabular}{lccccccc}
\hline & $\begin{array}{c}\text { Irrigated cropland } \\
\text { and pasture }^{\mathrm{b}}\end{array}$ & $\begin{array}{c}\text { Dryland cropland } \\
\text { and pasture }^{\mathrm{b}}\end{array}$ & $\begin{array}{c}\text { Deciduous } \\
\text { broadleaf forest }^{\mathrm{b}}\end{array}$ & Grassland $^{\mathrm{b}}$ & $\begin{array}{c}\text { Water } \\
\text { bodies }^{\mathrm{b}}\end{array}$ & $\begin{array}{c}\text { Urban and } \\
\text { built-up land }^{\mathrm{b}}\end{array}$ & Unused land $^{\mathrm{b}}$ \\
\hline $\begin{array}{l}\text { Irrigated cropland } \\
\text { and pasture }\end{array}$ & 97.32 & 0.32 & 2.04 & 0.02 & 0.15 & 2.88 & 0.03 \\
$\begin{array}{l}\text { Dryland cropland } \\
\text { and pasture }\end{array}$ & 0.23 & 98.74 & 3.43 & 2.02 & 0.05 & 3.2 & 0.2 \\
$\begin{array}{l}\text { Deciduous } \\
\text { broadleaf forest }^{\mathrm{a}}\end{array}$ & 0.54 & 0.04 & 96.45 & 4.43 & 0.23 & 0.3 & 0.22 \\
$\begin{array}{l}\text { Grassland } \\
\text { a }\end{array}$ & 0.34 & 0.26 & 5.23 & 93 & 0.4 & 0.54 & 0.17 \\
$\begin{array}{l}\text { Water bodies } \\
\text { Urban and built-up }\end{array}$ & 0.37 & 0.24 & 0.01 & 0.05 & 97.78 & 0.27 & 0.23 \\
land $^{\mathrm{a}}$ & 0 & 0 & 0 & 0 & 0 & 99.25 & 0 \\
Unused land $^{\mathrm{a}}$ & 0.02 & 0.1 & 0.07 & 0.12 & 0.14 & 0.69 & 90.86 \\
\hline
\end{tabular}

Note: ${ }^{\mathrm{a}, \mathrm{b}}$ represent land-cover and land-use types before and after reclassification.

Overall accuracy $=96.84 \%$, Kappa coefficient $=0.9503$.

simulation were used in this study. The $20 \mathrm{~km}$ resolution temperature data were obtained by interpolating the monthly average temperature data from the 57 meteorological stations in the North China Plain with the Kriging interpolation method.

\section{Results}

4.1. Characteristics of Land Cover Changes in the North China Plain during 1992-2005. Figure 2 shows the LUCC of the North China Plain, which was obtained by reclassification and upscaling of high resolution data. The map shows that the plain region was dominated by cropland, which accounted for $70 \%$ of the total area of the North China Plain. The irrigated cropland mainly concentrated in the northern part of Jiangsu Province and the southwestern part of Shandong Province. The deciduous broadleaf forest and grassland were mainly distributed in the mountainous and hilly areas, sea beaches, banks of lakes and rivers, and so forth. The deciduous broadleaf forest was mainly distributed along the southern part of Yanshan Mountain, eastern piedmont of Taihang Mountain, northern piedmont of Tongbai Mountain, and Dabie Mountain. While the grassland mainly concentrated in the hilly areas and coastal areas in Shandong Province. The urban and built-up land was scattered in the whole North China Plain and accounted for about $14 \%$ of the total land area.

The LUCC data of the North China Plain in 1992 and 2005 were overlaid to further analyze the conversion and inner change of each land cover type. The result indicated that the LUCC was mainly characterized by the increase in the urban and built-up land and decrease in the dryland cropland, the changing rate of which reached $2.12 \%$ and $1.59 \%$, respectively. By contrast, the changing rates of other land cover types were not more than $0.5 \%$. The result indicated that the newly increased urban and built-up land was mainly located in the Beijing-Tianjin-Tangshan zone and around large and medium-sized cities such as Shijiazhuang, Zhengzhou, Ji'nan, Qingdao, and Lianyungang; besides, the newly increased urban and built-up land mainly was converted from the dryland cropland, accounting for $60.55 \%$ of the conversion from the dryland cropland (Figure 3).

4.2. Ability of the WRF Model to Simulate the Temperature Change in the North China Plain. The test result obtained with the standard WRF model was first compared with the ground-based observation data to assess the ability of the WRF model to simulate the climate in the North China Plain. The daily average temperature was calculated as the average value of the temperature at 00:00, 06:00, 12:00, and 18:00 so as to keep it consistent with the ground-based observation criteria. The result indicates that the WRF model can simulate the spatiotemporal change of temperature very well (Figure 4). According to the monthly change of the daily average temperature in the whole study area, the highest temperatures in the observation data and simulation data both appear around July, and the lowest temperatures in the observation data and simulation data both appear around January. The decreasing rate of the temperature during September and November is a bit higher than that during March and May; that is, the temperature decreases a little more quickly in the autumn than it increases in the Spring.

According to the spatial pattern of the daily average temperature in February and August, the simulation data and the ground-based observation data both indicate that the temperature is lower in the north part and higher in the south part, it is colder in the mountainous area and warmer in the plain area in the regions at the same latitude, and it is warmer in the inland region than in the coastal region. For example, the temperature difference between the Fuyang observation station in the extreme north and the Zunhua observation station in the extreme north is as high as $5^{\circ} \mathrm{C}$ in February and $2-3^{\circ} \mathrm{C}$ in August. While that between the Chengshantou observation station in the extreme east and the Shijiazhuang observation station in the extreme west is $1-1.5^{\circ} \mathrm{C}$ and $0.2-$ $0.3^{\circ} \mathrm{C}$, respectively (Figure 5 ).

There is still some difference between the observed and simulated temperatures; that is, the simulated temperature is 


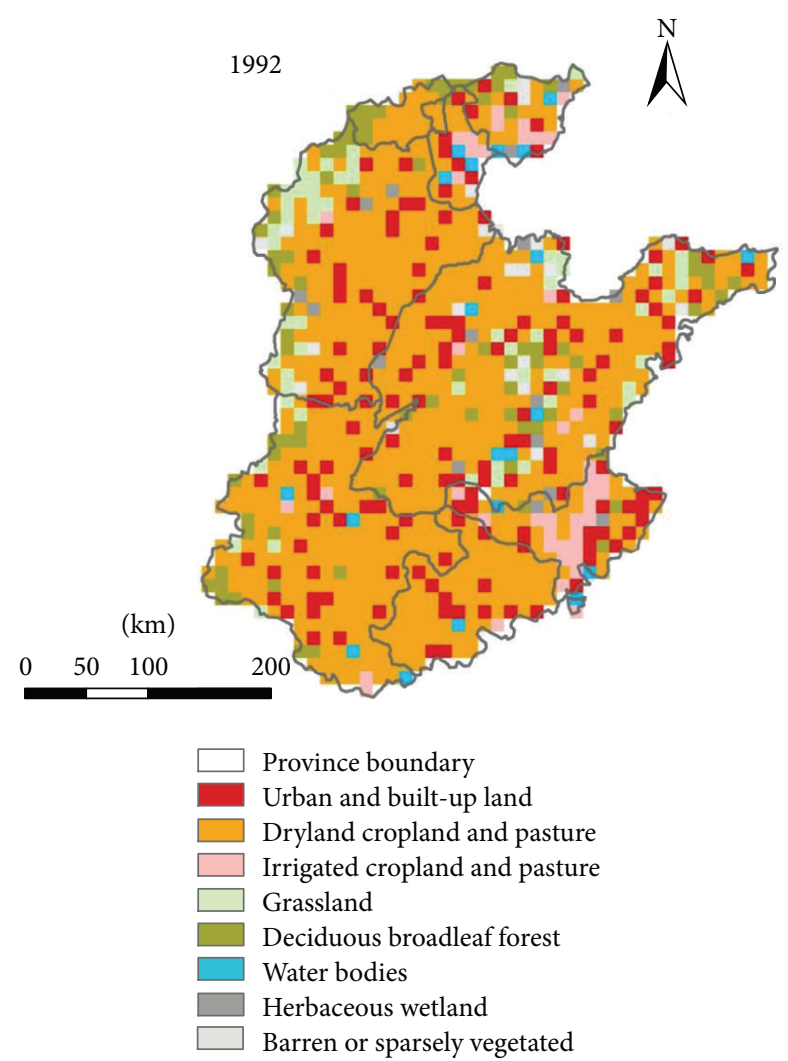

(a)

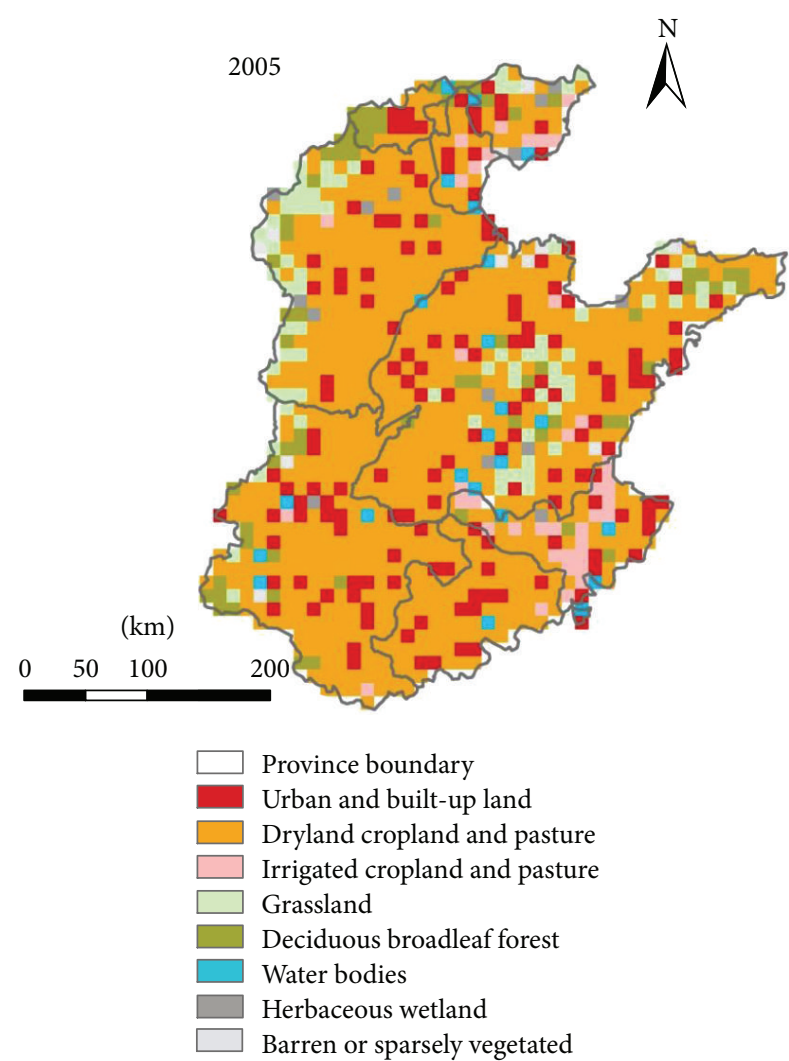

(b)

Figure 2: The LUCC map after upscaling in 1992 and 2005.
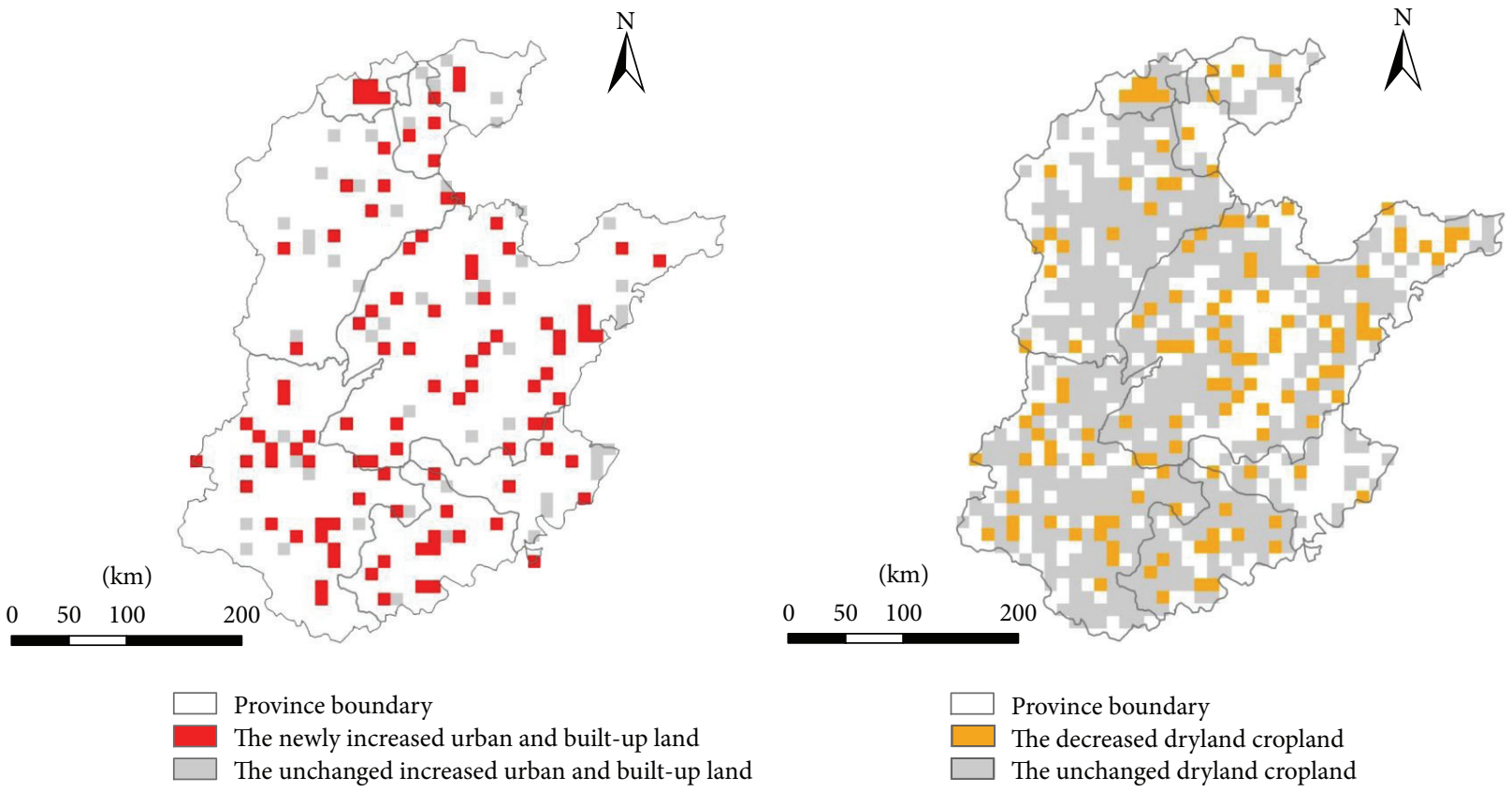

(b)

FiguRE 3: Map of the unchanged and newly increased urban and built-up land (a) and map of the unchanged and decreased dryland cropland (b). 


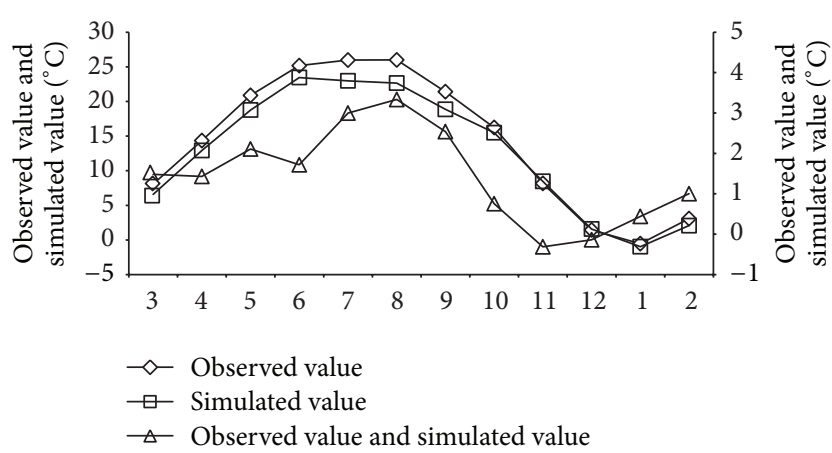

FIGURE 4: Comparisons of simulated and observed values of the monthly average temperature at 2 meters above the ground.

lower than the observed temperature on the whole. The one reason is that there is systematic error in the WRF model. When simulating the surface temperature of East Asia with the regional climate model, cold deviation is a widespread phenomenon.

The annual daily average temperature of the 57 observation stations is $14.19^{\circ} \mathrm{C}$ on average, while the simulated value is $12.74^{\circ} \mathrm{C}$. According to the monthly temperature change, the simulated value is lower than the observed value in most months except November and December, and the maximum difference between them reaches $3.34^{\circ} \mathrm{C}$ in August. By contrast, the data of the seasonal temperature change suggests that the simulated temperature is lower than the observed temperature in all seasons. The difference is most significant in the summer, reaching $2.68^{\circ} \mathrm{C}$, while it is relatively small in the spring, autumn, and winter, being $1.67^{\circ} \mathrm{C}, 0.99^{\circ} \mathrm{C}$, and $0.44^{\circ} \mathrm{C}$, respectively (Table 6).

There are also some differences in the spatial patterns of the observed and simulated temperatures. In comparison with the observed temperature, the simulated temperature is higher in the mountainous area and lower in the plain area. For example, there is a large difference between the observed and simulated daily average temperature in February and August. There are 49 observation stations with significant difference between the observed and simulated daily average temperatures (reaching the significance level of 95\%) in February, of which 39 stations have the simulated value $2.00^{\circ} \mathrm{C}$ lower than the observed value on average. While the simulated temperature of the other 10 observatio while the observation stations $\mathrm{n}$ stations is $1.09^{\circ} \mathrm{C}$ higher than the observed temperature on average. The observation stations with the lower simulated temperature are mainly located in the middle part of Hebei Province and Shandong Province, while that with the higher simulated temperature mainly concentrates in the eastern piedmont of Taihang Mountain and inner part of Henan Province. By contrast, the differences between the observed and simulated daily average temperatures in August in 42 observation stations reach the significance level. The simulated value of the 17 out of the 42 observation stations is $0.51^{\circ} \mathrm{C}$ lower than the observed value on average, while the simulated temperature of the other 25 observation stations is $0.98^{\circ} \mathrm{C}$ higher than the observed one on average. The observation stations with the lower simulated temperature are mainly located in Henan Province and Hebei Province, while the observation stations with the higher simulated temperature mainly concentrate in the hilly area in Shandong Province and the Beijing-TianjinTangshan zone (Figure 6).

In summary, the analysis mentioned above indicates that the WRF model can simulate the seasonal change and spatial pattern of temperature in the North China Plain very well. Although there is some difference between the observed and simulated value, with the simulated temperature being lower than the observed temperature on the whole, there is no significant difference in the spatial patterns of the observed and simulated temperatures on the whole. There is only some large difference in very few areas, indicating that the WRF model has a great advantage in the simulation of the climate in the plain area.

4.3. Analysis of Test Results. The LUCC in the North China Plain, which was characterized by the regional urbanization, had led to some change of the near-surface temperature. The annual average temperatures in the control test and sensitivity test were $14.61^{\circ} \mathrm{C}$ and $14.64^{\circ} \mathrm{C}$, respectively. The LUCC in the North China Plain made the regional nearsurface temperature increase by $0.03^{\circ} \mathrm{C} /$ year. All the months except January and June were characterized by a temperature increase during 1992-2005. Besides, the LUCC in the North China Plain also led to an increase in the near-surface temperature in all the seasons, among which the temperature increment was the highest in the summer and the lowest in the winter, reaching $0.05^{\circ} \mathrm{C}$ and $0.02^{\circ} \mathrm{C}$, respectively. The monthly and seasonal temperature differences in the control test and sensitivity test were as shown in Figure 7.

The spatial patterns of the temperature increase are consistent in the spring and autumn on the whole, both indicating a significant temperature increase in the North China Plain (Figure 8). The amplitude of the temperature increase is relatively small in the spring (generally around $0.03^{\circ} \mathrm{C}$ ), while it is very large in the autumn (above $0.04^{\circ} \mathrm{C}$ on average). The temperature increases most greatly in the summer, increasing by $0.05^{\circ} \mathrm{C} /$ year on average, exceeding $0.1^{\circ} \mathrm{C}$ in the Circum-Bohai-Sea region, and reaching $0.2^{\circ} \mathrm{C}$ in the Beijing-Tianjin-Tangshan zone. Besides, there are much wider regions with a significant temperature in the summer than in the other three seasons. Although the temperature increases in the winter on the whole, it still decreases in most regions, especially in the Yanshan Mountain, Circum-BohaiSea region, Shandong Peninsula, and so forth.

The spatial pattern of the seasonal temperature change corresponded to that of the LUCC on the whole. The temperature generally increased in the regions where the urban and built-up land increases. The temperature increment was very high in these regions, and the degree and range of influence of the temperature increase varied very significantly among seasons. Taking the Beijing-Tianjin-Tangshan zone as an example, the temperature increment was very large and the range of the influence of the temperature rise was very wide in the summer in this region. The regional temperature 


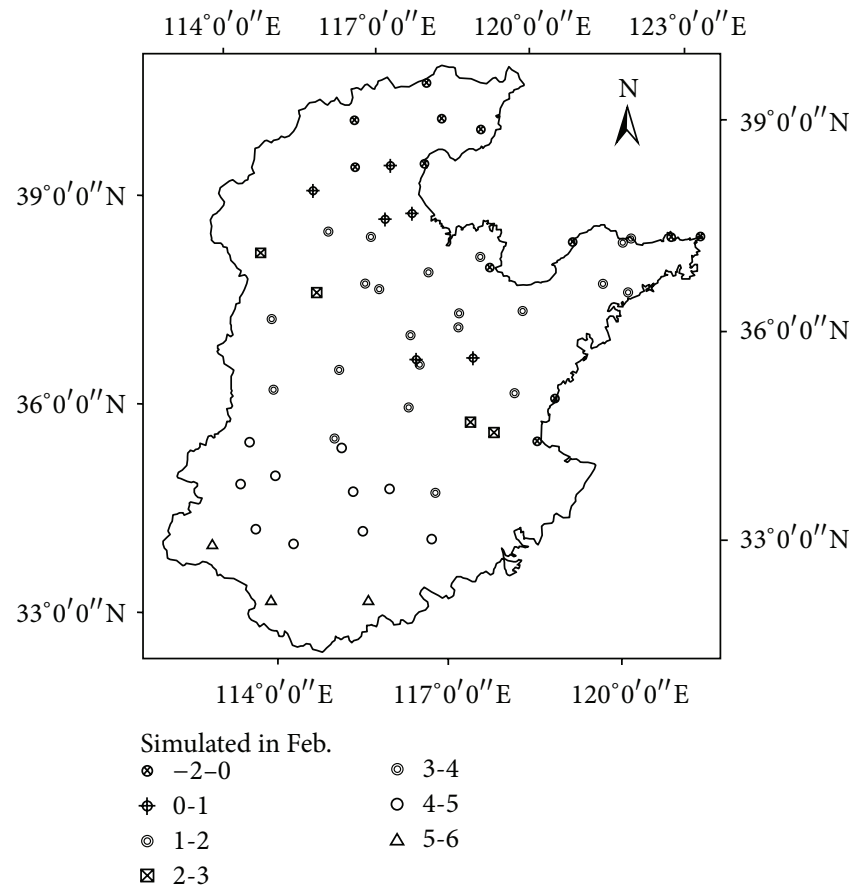

(a)

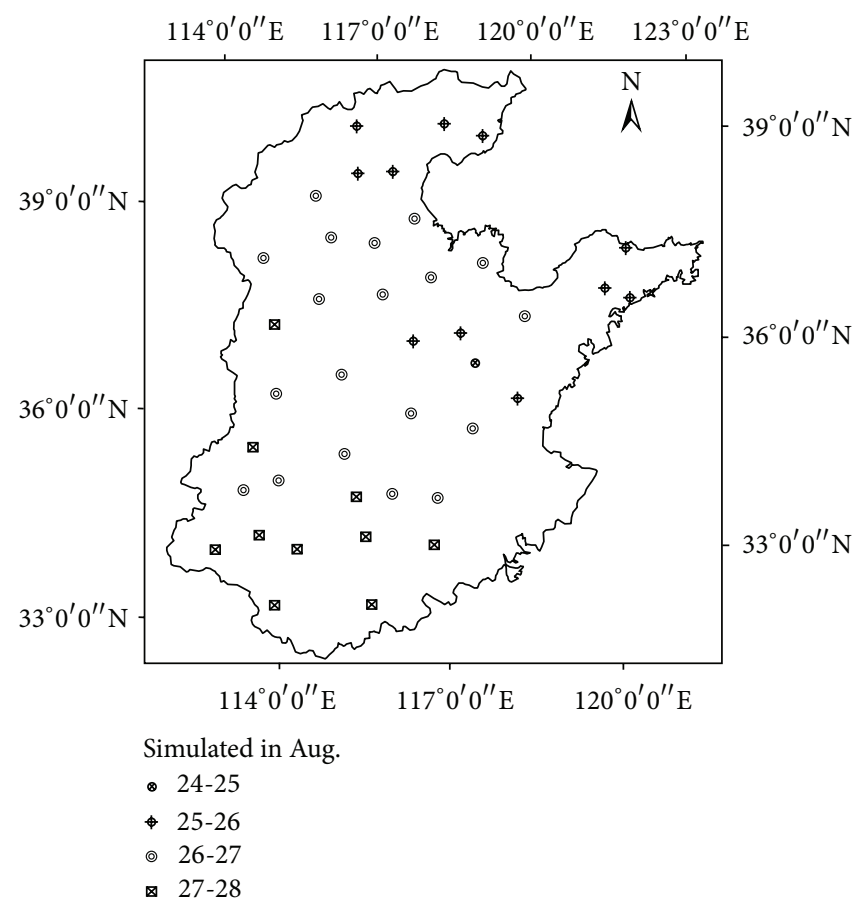

(b)

FIgURE 5: Simulated value of the daily average temperature in the North China Plain in February and August.

TABLE 6: Simulated and observed values of the seasonal average temperature at 2 meters above the ground surface in the North China Plain (unit: ${ }^{\circ} \mathrm{C}$ ).

\begin{tabular}{|c|c|c|c|c|}
\hline & Winter & Spring & Summer & Autumn \\
\hline Simulated value & 0.89 & 12.76 & 23.03 & 14.27 \\
\hline Observed value & 1.33 & 14.43 & 25.72 & 15.27 \\
\hline Difference between simulated value and observed value & 0.44 & 1.67 & 2.68 & 0.99 \\
\hline
\end{tabular}

increased by $0.06-2.8^{\circ} \mathrm{C}$ in the summer, and the temperature change due to expansion of the urban and built-up land influenced a wide area around the Beijing-Tianjin-Tangshan zone. The temperature increment was largely the same in the spring and autumn, reaching $0.03-3^{\circ} \mathrm{C}$. However, the temperature rise mainly influenced Beijing and Tianjin in the spring and Beijing and some area in the north part of Hebei Province in the autumn. The temperature rise was only obvious in the regions where the urban and builtup land increased, while in other regions the temperature generally decreased by $0.01-0.06^{\circ} \mathrm{C}$, which might be because the wind velocity was generally very high in the north China in the winter and consequently reduced the temperature rise resulting from the increase in urban and built-up land $[12,13]$.

The temperature changes most greatly in the urban and built-up land among all the land cover types in the North China Plain $\left(0.1^{\circ} \mathrm{C} /\right.$ year $)$, followed by the irrigated cropland and pasture $\left(0.06^{\circ} \mathrm{C} /\right.$ year $)$, while the temperature increases most slightly in the grassland, with an increment of only $0.01^{\circ} \mathrm{C} /$ year (Figure 9). The result is largely consistent with the result of the research of Lim et al. [14], in which the climate in the northern hemisphere was simulated with the "CRUNNR" model at the $5^{\circ} \times 5^{\circ}$ resolution (the OMR trend value of the urban and built-up land, crop land, broadleaf forest, and bare land was $0.034^{\circ} \mathrm{C} /$ year, $0.02^{\circ} \mathrm{C} /$ year, $0.002^{\circ} \mathrm{C} /$ year, and $0.02^{\circ} \mathrm{C} /$ year, resp.). However, the simulated result is still somewhat higher, which may be because the ERA40 reanalysis indirectly included the ground-based observation data and consequently made the OMR trend values smaller than the results obtained with the numerical simulation.

The vegetation plays an important role in influencing the near-surface temperature. For example, one of the main reasons for the near-surface temperature changes in different land cover and land use types is the amount and density of the vegetation. On the whole, the better the vegetation cover is, the less the temperature riseis. It may be because there is very little evaporation in the barren land, and the land surface heat mainly gets into the atmosphere in the form of sensible heat. By contrast, there is higher soil humidity in the densely vegetated land, which makes the land surface heat mainly get into the atmosphere in the form of latent heat and consequently reduces part of the temperature rise 


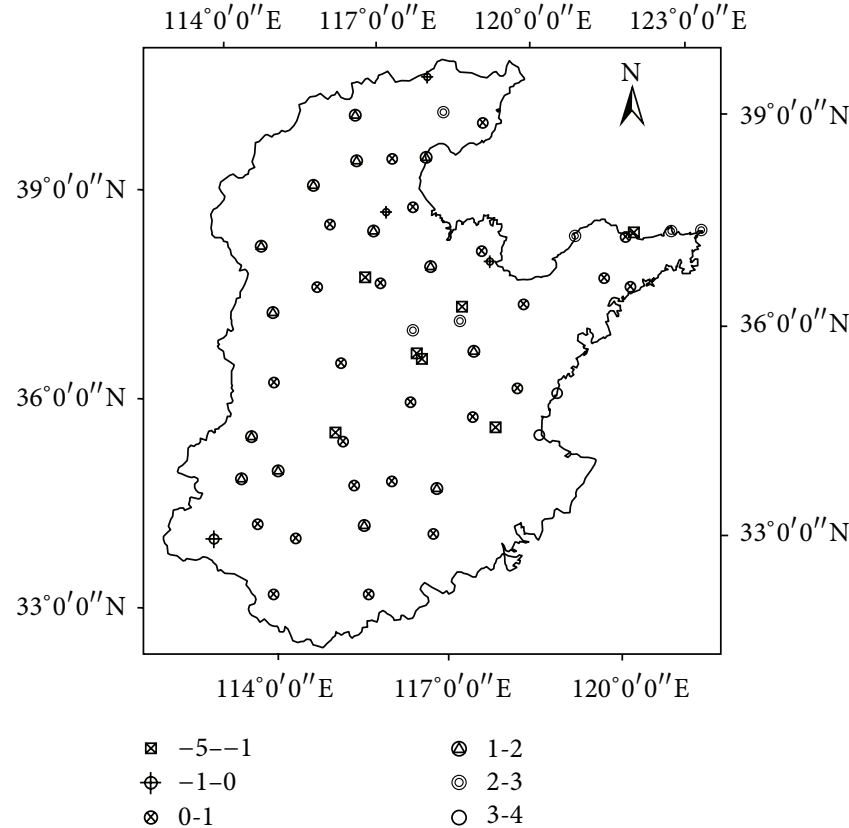

(a)

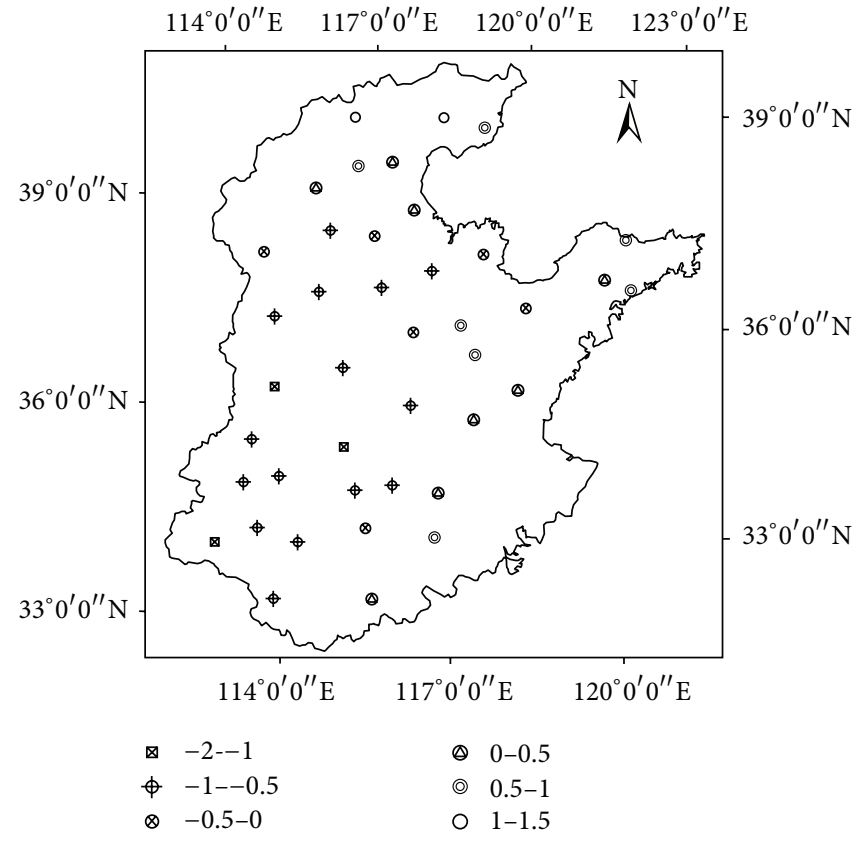

(b)

Figure 6: Difference between the observed and simulated daily average temperature in the North China Plain in February and August.

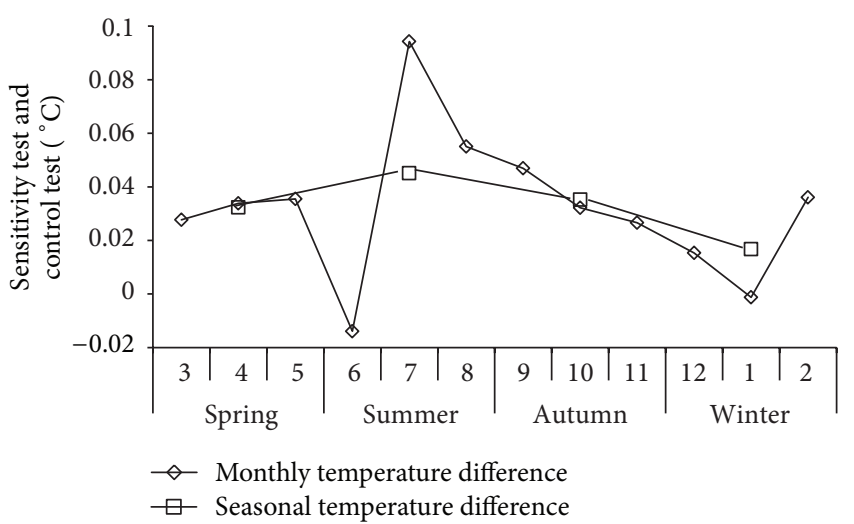

FIgURE 7: Monthly and seasonal temperature differences in the control test and sensitivity test.

of the land surface. In addition, the heat island effect in the urban region also leads to the rise of the near-surface temperature. By contrast, the temperature increment is less in the water bodies, mainly because the specific heat capacity of water bodies is very large, which makes the temperature increase very slowly and consequently makes the near-surface temperature lower [15]. Moreover, there is great difference between the irrigation intensities of the dryland cropland and irrigated cropland, which leads to great difference in the physical characteristics of them and consequently makes the temperature increments differ greatly.
The change of the average near-surface temperature corresponding to each kind of land cover change was summarized in this study. The following figure shows the temperature change in the eight major types of land cover change that involve a large area of land (Figure 10). The result showed that the conversion from dryland crop to forest and built-up land made the near-surface temperature increase by $0.13^{\circ} \mathrm{C} /$ year, while the conversion from dryland crop to grassland made the near-surface temperature decrease by $0.1^{\circ} \mathrm{C} /$ year. By contrast, the other conversion types only made the near-surface temperature increase by $0.01-0.04^{\circ} \mathrm{C} /$ year.

The conversion from croplands to built-up lands can lead to the changes in the roughness and albedo of the land surface, further cause the change in the radiation flux of the land surface, and consequently make the regional near-surface temperature increase. Besides, changes of the underlying surface due to the urbanization can alter the physical processes such as the energy balance of the land surface, lead to the "five island effects" (i.e., dark islands, heat islands, dry islands, wet islands, and rain islands), decrease the wind velocity and result in the variable city climate, and consequently influence the structure and development of the boundary layer and change the climate in a large area. Moreover, the conversion from grasslands to dryland croplands can decrease the albedo of the land surface, increase the net radiation of land surface, and consequently make the sensible heat increase and lead to the increase of the daily average temperature. The conversion from dryland cropland to forest makes the near-surface temperature increase, mainly because agricultural irrigation can usually make the evapotranspiration and air humidity increase, which leads to the 


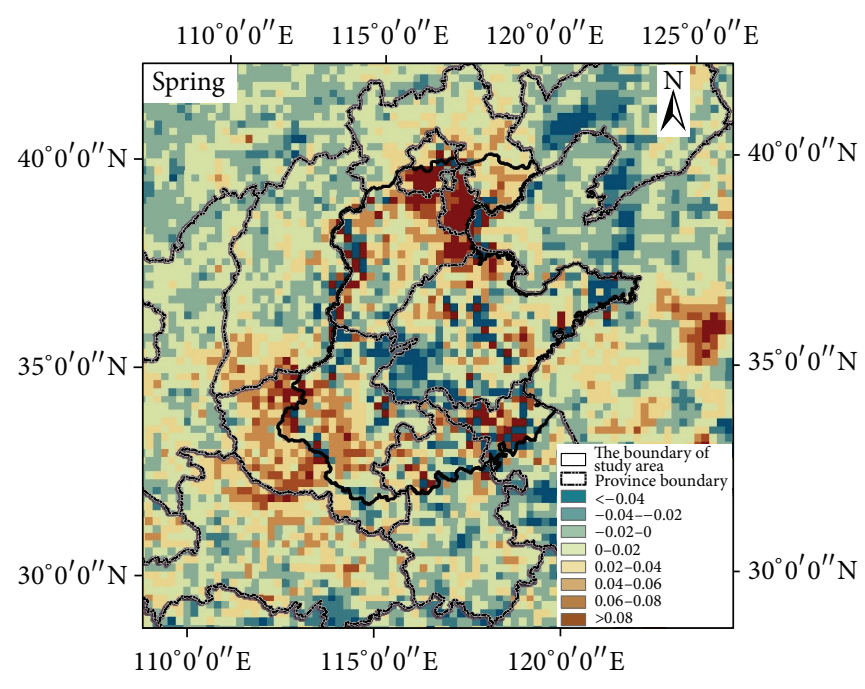

(a)

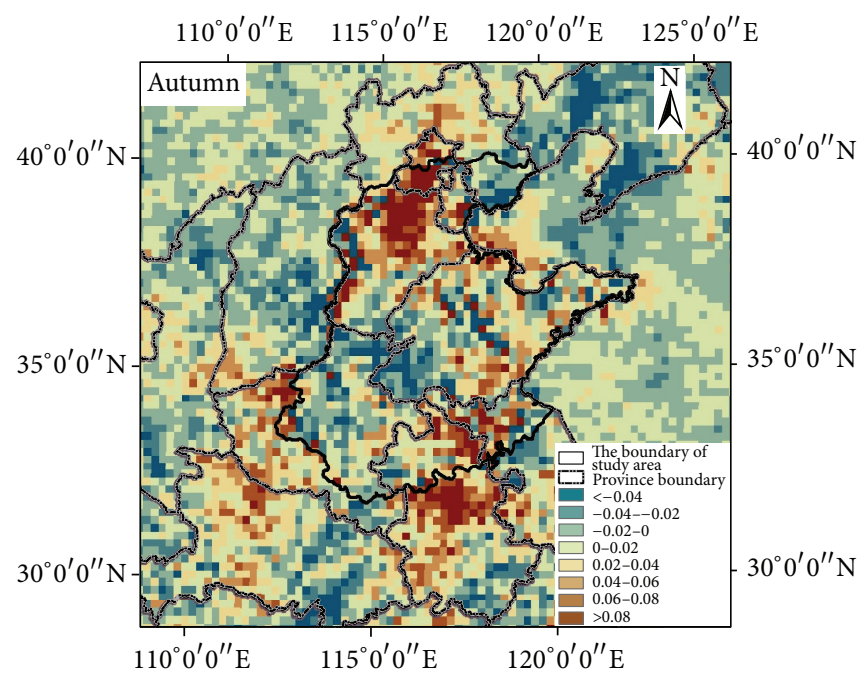

(c)

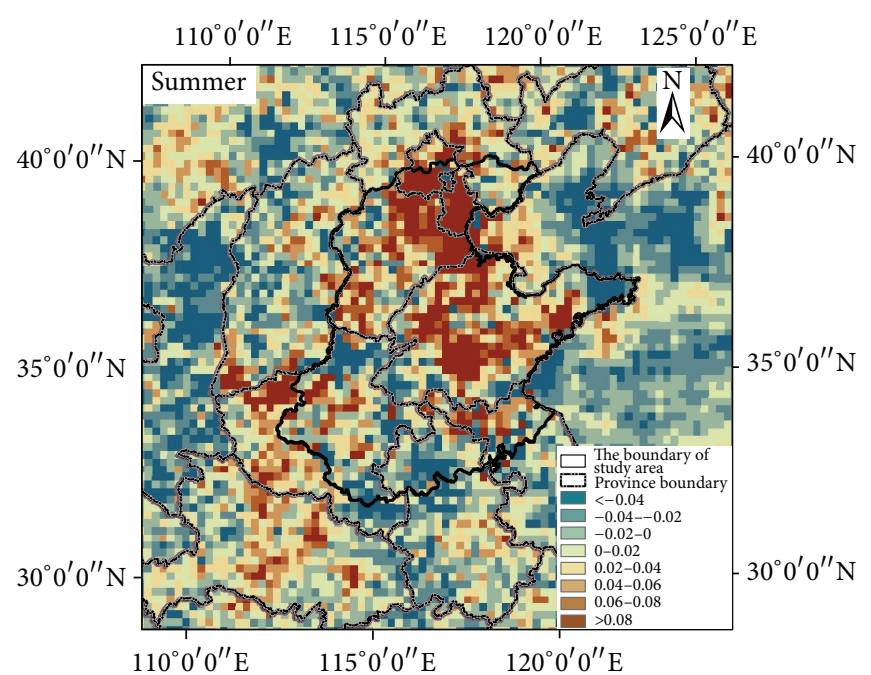

(b)

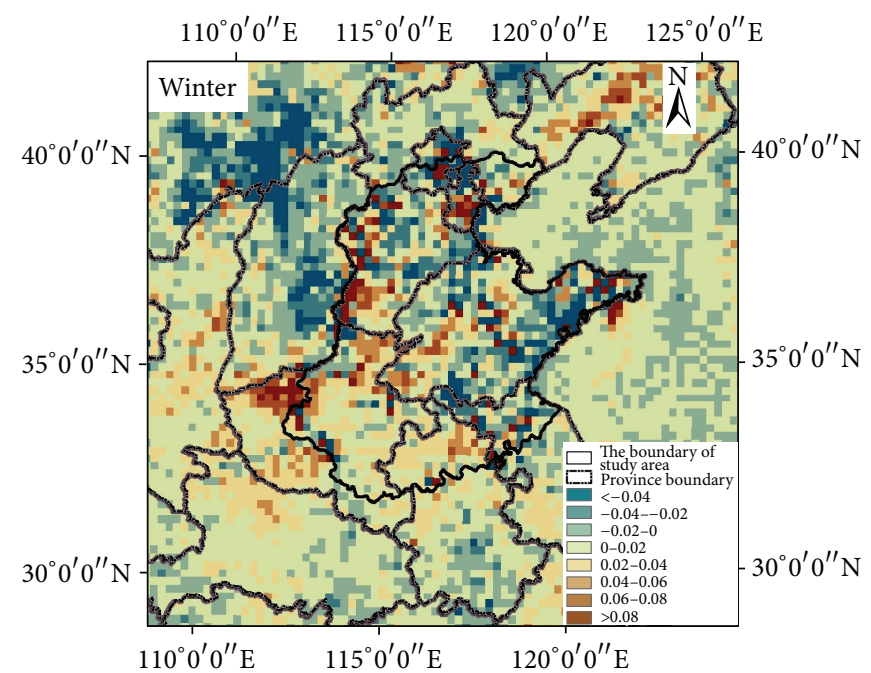

(d)

Figure 8: Difference between the near-surface temperature in the four seasons in the sensitivity test and control test (Unit: $\left.{ }^{\circ} \mathrm{C}\right)$.

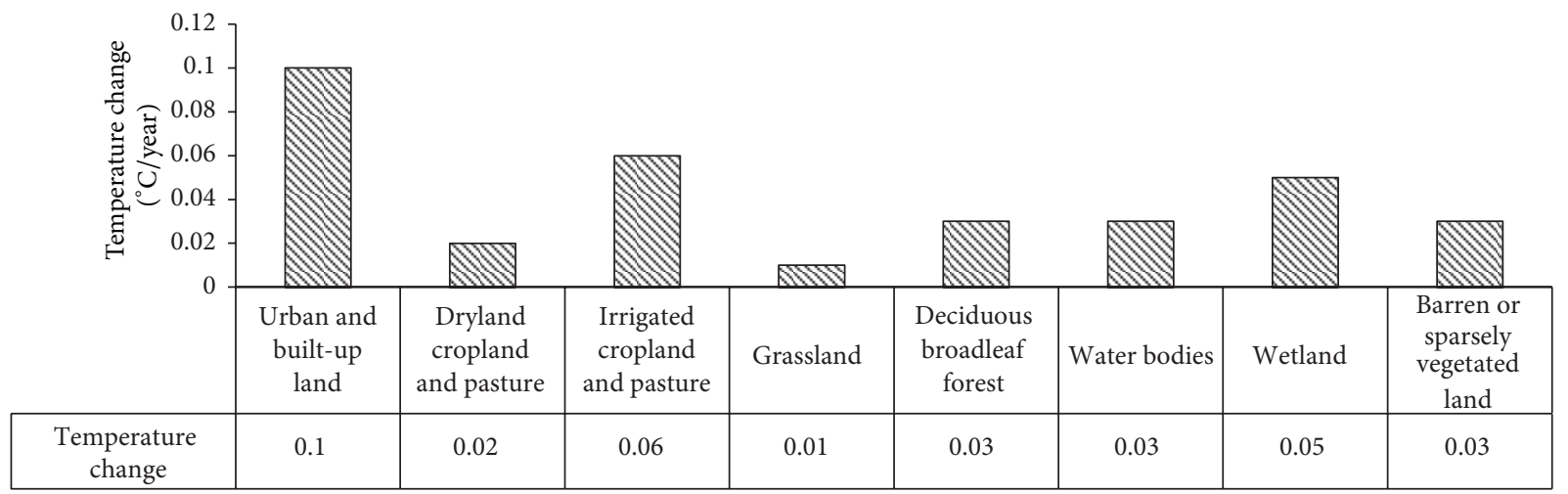

FIgURE 9: Temperature change in various land cover types. 


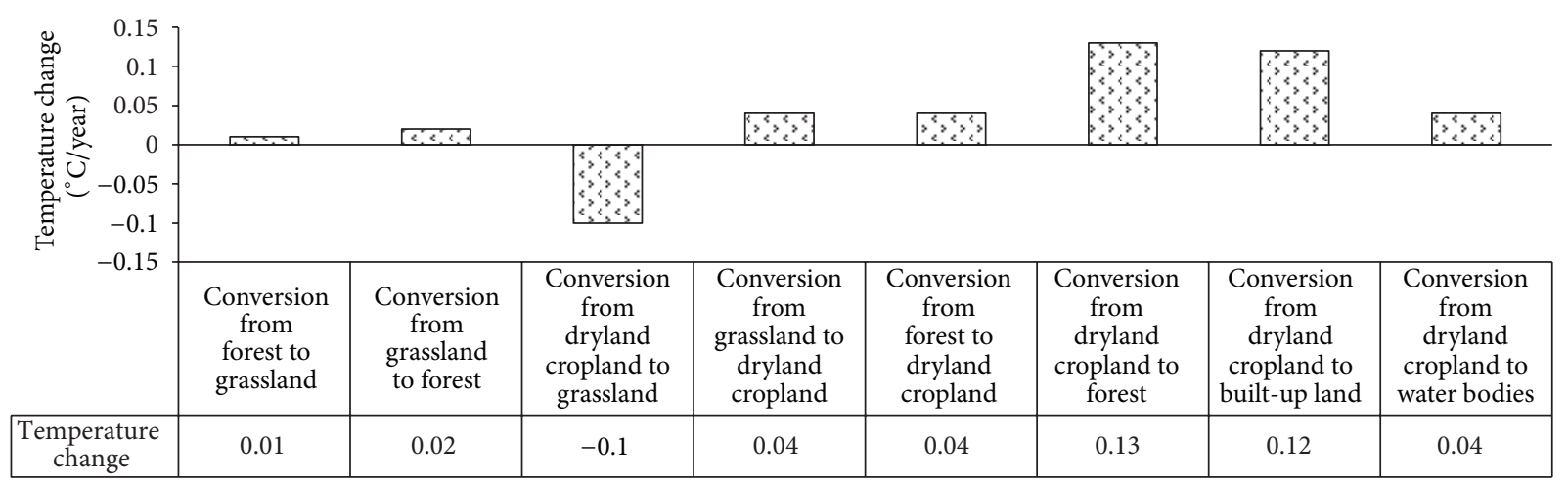

FIGURE 10: Change of the near-surface temperature corresponding to each type of land cover change.

increasing of the dew point temperature (when the pressure is $1000 \mathrm{~Pa}$, Dew point temperature rising of $1^{\circ} \mathrm{C}$ is equivalent to temperature increasing of $2.5^{\circ} \mathrm{C}$ ).

\section{Conclusion and Discussion}

The regional climate model, the WRF model, was used to study the impacts of land cover change on the near-surface temperature in the North China Plain on the basis of the land cover data of the North China Plain in year 1992 and year 2005 in this study. The land cover change in the North China Plain during 1992-2005 was mainly characterized by the increase in urban and built-up lands and the decrease in dryland croplands. The urban and built-up lands increased by $2.12 \%$, and the dryland cropland decreased by $1.59 \%$, while other land cover types changed by no more than $0.5 \%$. Besides, the newly increased urban and built-up land was mainly located in the Beijing-Tianjin-Tangshan zone and around large and medium-sized cities such as Shijiazhuang, Zhengzhou, Jinan, Qingdao, and Lianyungang. In addition, the newly increased urban and built-up land mainly was converted from the dryland cropland and accounted for $60.55 \%$ of the conversion from the dryland cropland during this period.

The WRF model can reflect the seasonal change and spatial pattern of the near-surface temperature in the North China Plain very well, although there is some difference between the observed and simulated values, with the simulated temperature being a little lower on the whole. There is no significant difference in the spatial patterns of the observed and simulated temperatures on the whole, except some slightly large difference in few areas. The result indicates that the WRF model has a substantial advantage in simulating the climate in the plain area. The land cover change in the North China Plain, which was mainly characterized by the regional urbanization, has caused significant change of the near-surface temperature. It led to a regional nearsurface temperature increment of $0.03^{\circ} \mathrm{C} /$ year. Besides, the spatial pattern of the temperature change corresponded to that of the land cover change on the whole; that is, the temperature mainly increased significantly in the regions where the urban and built-up land expanded; In addition, the degree and range of the influence of the temperature rise varied greatly among seasons. The temperature changed most significantly in the urban and built-up land $\left(0.1^{\circ} \mathrm{C} /\right.$ year $)$, followed by the irrigated cropland and pasture $\left(0.06^{\circ} \mathrm{C} /\right.$ year $)$. The temperature generally changed by $0.02-0.05^{\circ} \mathrm{C} /$ year in the forest, water bodies, and dryland cropland and pasture, and it changed most slightly in the grassland $\left(0.01^{\circ} \mathrm{C} /\right.$ year $)$. Among all the types of land cover change that involved a large land area, the conversion from dry land into forest and built-up land led to the greatest near-surface temperature increment, reaching $0.13^{\circ} \mathrm{C} /$ year. While the conversion from dry land and pasture into grassland made the near-surface temperature decrease by $0.1^{\circ} \mathrm{C} /$ year. By contrast, the other conversions only made the near-surface temperature change by $0.01-0.04^{\circ} \mathrm{C} /$ year.

Different types of land cover differ greatly in the physical characteristics, chemical processes, and biological processes, which lead to the significant differences in the energy budget and water budget of the land surface and consequently have different impacts on the regional climate change. In comparison to the increase in the greenhouse gases that has a global influence, the land cover changes exert more influence at the regional scale. The land-atmosphere feedback can change the albedo and soil moisture, alter the evaporation process, and consequently influence the response of the regional nearsurface temperature to the increase in the greenhouse gases. Generally, the better the vegetation cover is, the less the temperature riseis. For example, the urban heat island effect in the urban regions where there is less vegetation will lead to greater increase in the near-surface temperature. Besides, the temperature increment in the water bodies is generally lower and consequently leads to a lower near-surface temperature since the water has a large specific heat capacity and its temperature generally increases more slowly. In addition, the significant difference between the irrigation intensities of the dryland cropland and that of the irrigated cropland also leads to great difference in their physical characteristics and consequently makes their temperature increments differ greatly. Moreover, the change of the underlying surface due to the urbanization can alter the physical processes such as the energy balance of the land surface and consequently lead to the climate change in a large area; for example, the 
conversion from the cropland to the urban and built-up land can change the roughness and albedo of the land surface and consequently cause the change in the radiation flux of the land surface and lead to significant increase in the regional nearsurface temperature.

There are still some uncertainties in the research on the climatic effects of the land cover change, so it is still necessary to carry out more in-depth researches on a series of issues such as the improvement of the climate model and the reclassification method of the land cover change data, especially the land cover data. Since this study is preliminary, there are still some deficiencies as follows. First, there is still some difference between the upscaled land cover data and the initial data, which leads to some uncertainties in the simulated climatic effects of the land cover change. Second, the result may change if the calculus of the data of a long period is carried out since the study of the impacts of the land cover change on the temperature in the North China Plain is based on the sensitivity test of the numerical integration of the data of only two years in this <study. In addition, there are some uncertainties in the result since there are various feedbacks within the climate system. In view of these deficiencies, on the one hand, it is necessary to try more methods to upscale the data so as to reduce the influence of the errors in the data conversion. On the other hand, it is necessary to extend the integration time so as to guarantee the certainties of the simulation result.

\section{Acknowledgments}

This research was financially supported by the Ministry of Science and Technology of China (Grant no. 2010CB950904) and the National Natural Science Foundation of China (Grant no. 41071343).

\section{References}

[1] National Research Council, "Radiative forcing of climate change: expanding the concept and addressing uncertainties," Tech. Rep., National Research Council, Washington, DC, USA, 2005.

[2] M. Cai and E. Kalnay, "Response to the comments by Vose et al. and Trenberth. Impact of land-use change on climate," Nature, vol. 95, pp. 427-214, 2004.

[3] J. J. Feddema, K. W. Oleson, G. B. Bonan et al., "Atmospheric science: the importance of land-cover change in simulating future climates," Science, vol. 310, no. 5754, pp. 1674-1678, 2005.

[4] R. Mahmood, S. A. Foster, and D. Logan, "The GeoProfile metadata, exposure of instruments, and measurement bias in climatic record revisited," International Journal of Climatology, vol. 26, no. 8, pp. 1091-1124, 2006.

[5] A. Jazcilevich, V. Fuentes, E. Jauregui, and E. Luna, "Simulated urban climate response to historical land use modification in the Basin of Mexico," Climatic Change, vol. 44, no. 4, pp. 515536, 2000.

[6] A. D. Jazcilevich, A. R. García, and L. G. Ruíz-Suárez, "A modeling study of air pollution modulation through land-use change in the Valley of Mexico," Atmospheric Environment, vol. 36, no. 14, pp. 2297-2307, 2002.
[7] A. D. Jazcilevich, A. R. García, and L. G. Ruíz-Suárez, "A study of air flow patterns affecting pollutant concentrations in the Central Region of Mexico," Atmospheric Environment, vol. 37, no. 2, pp. 183-193, 2003.

[8] Q. P. Li and Y. H. Ding, "Research progress in the effect of vegetation change on regional climate," Journal of Nanjing Institute of Meteorology, vol. 27, no. 1, pp. 131-140, 2004.

[9] J. Chen, P. Zhao, H. Liu, and X. Guo, "Modeling impacts of vegetation in western China on the summer climate of northwestern China," Advances in Atmospheric Sciences, vol. 26, no. 4, pp. 803-812, 2009.

[10] A. Seth and F. Giorgi, "The effects of domain choice on summer precipitation simulation and sensitivity in a regional climate model," Journal of Climate, vol. 11, no. 17, pp. 2698-2712, 1998.

[11] S. Y. Liu, CWRF Application in East China Monsoon Area, Nanjing University of Information Science and Technology, Nanjing, China, 2006.

[12] A. J. Arnfield, "Two decades of urban climate research: a review of turbulence, exchanges of energy and water, and the urban heat island," International Journal of Climatology, vol. 23, no. 1, pp. 1-26, 2003.

[13] G. T. Johnson, T. R. Oke, T. J. Lyons, D. G. Steyn, I. D. Watson, and J. A. Voogt, "Simulation of surface urban heat islands under 'IDEAL' conditions at night part 1: theory and tests against field data," Boundary-Layer Meteorology, vol. 56, no. 3, pp. 275-294, 1991.

[14] Y. Lim, M. Cai, E. Kalnay, and L. Zhou, "Observational evidence of sensitivity of surface climate changes to land types and urbanization," Geophysical Research Letters, vol. 32, no. 22, Article ID L22712, 4 pages, 2005.

[15] W. Z. Su, Y. B. Yang, and G. S. Yang, "Distributional characteristics of urban thermal space and relations with land use/cover of Nanjing," Scientia Geographica Sinica, vol. 25, no. 6, pp. 697703, 2005. 

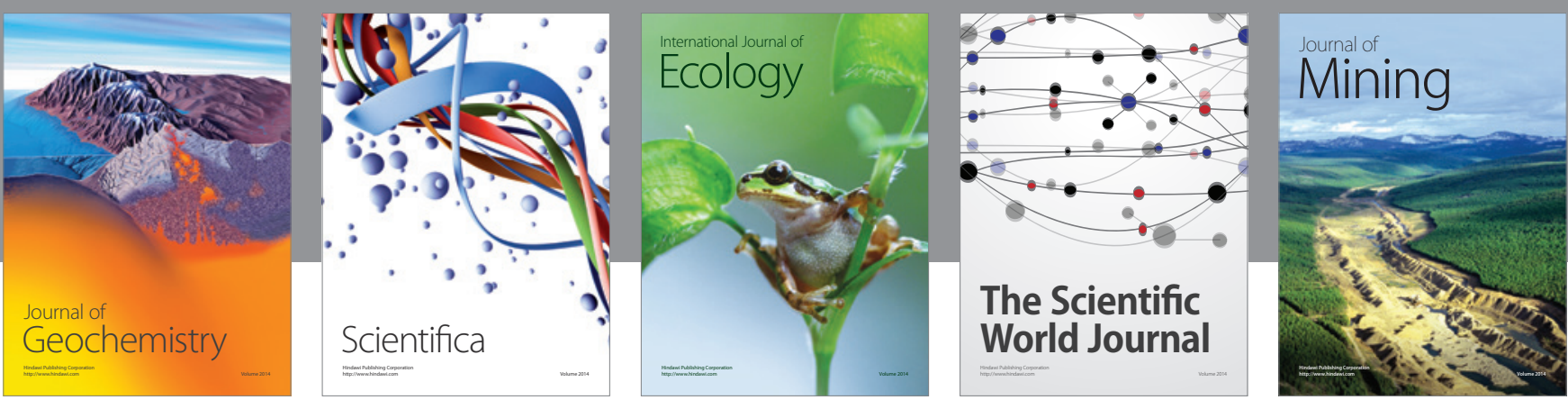

The Scientific World Journal
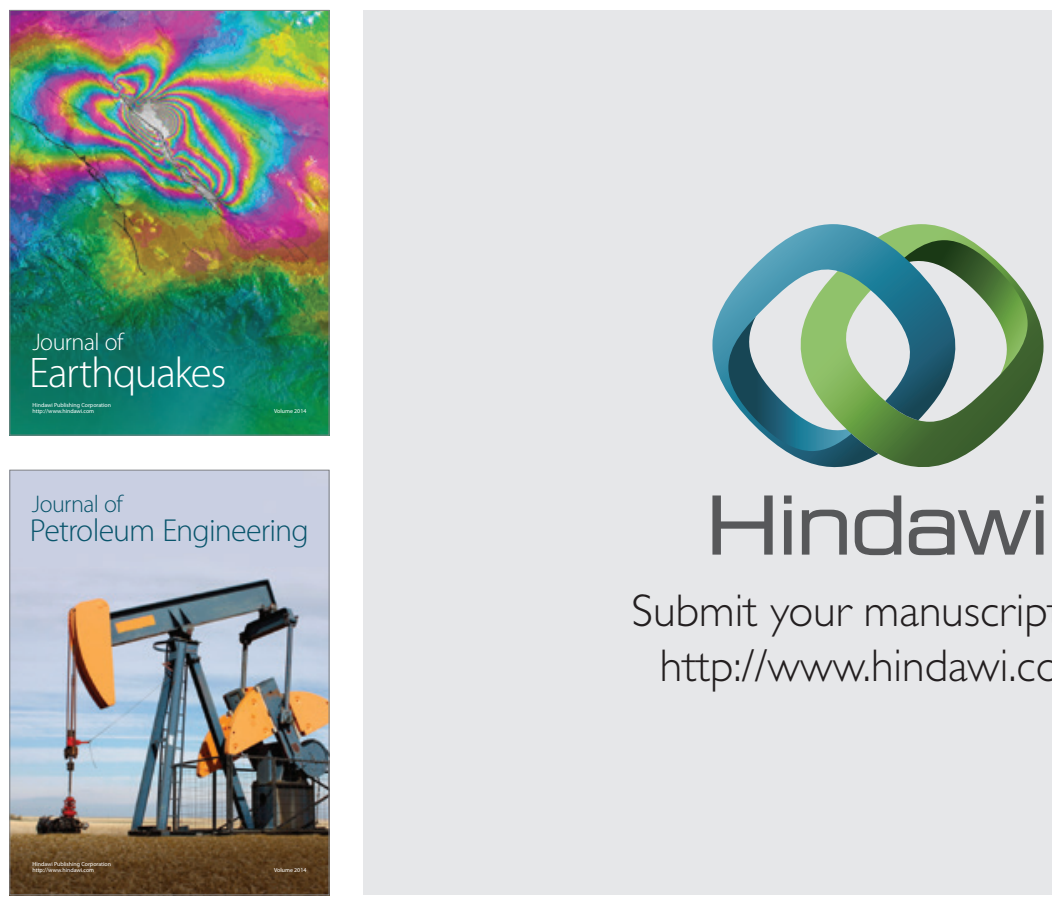

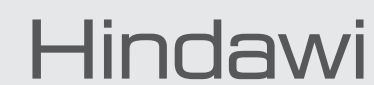

Submit your manuscripts at

http://www.hindawi.com
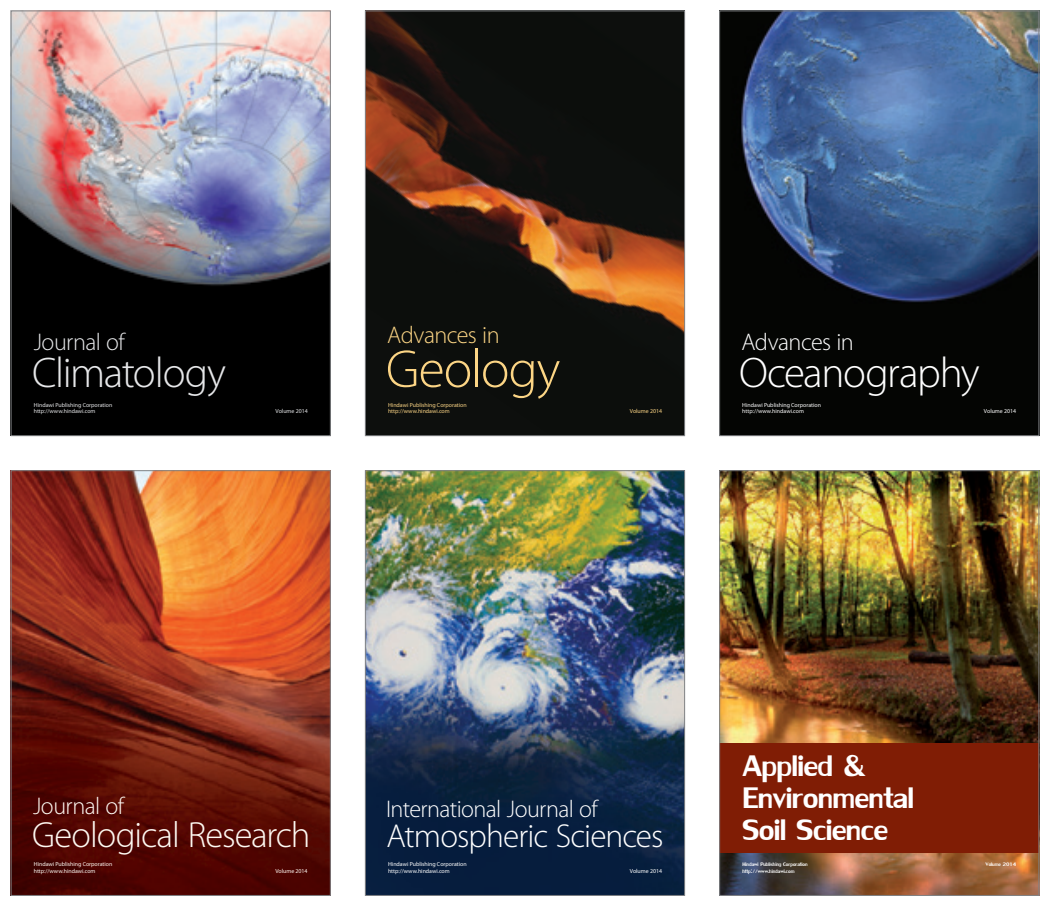
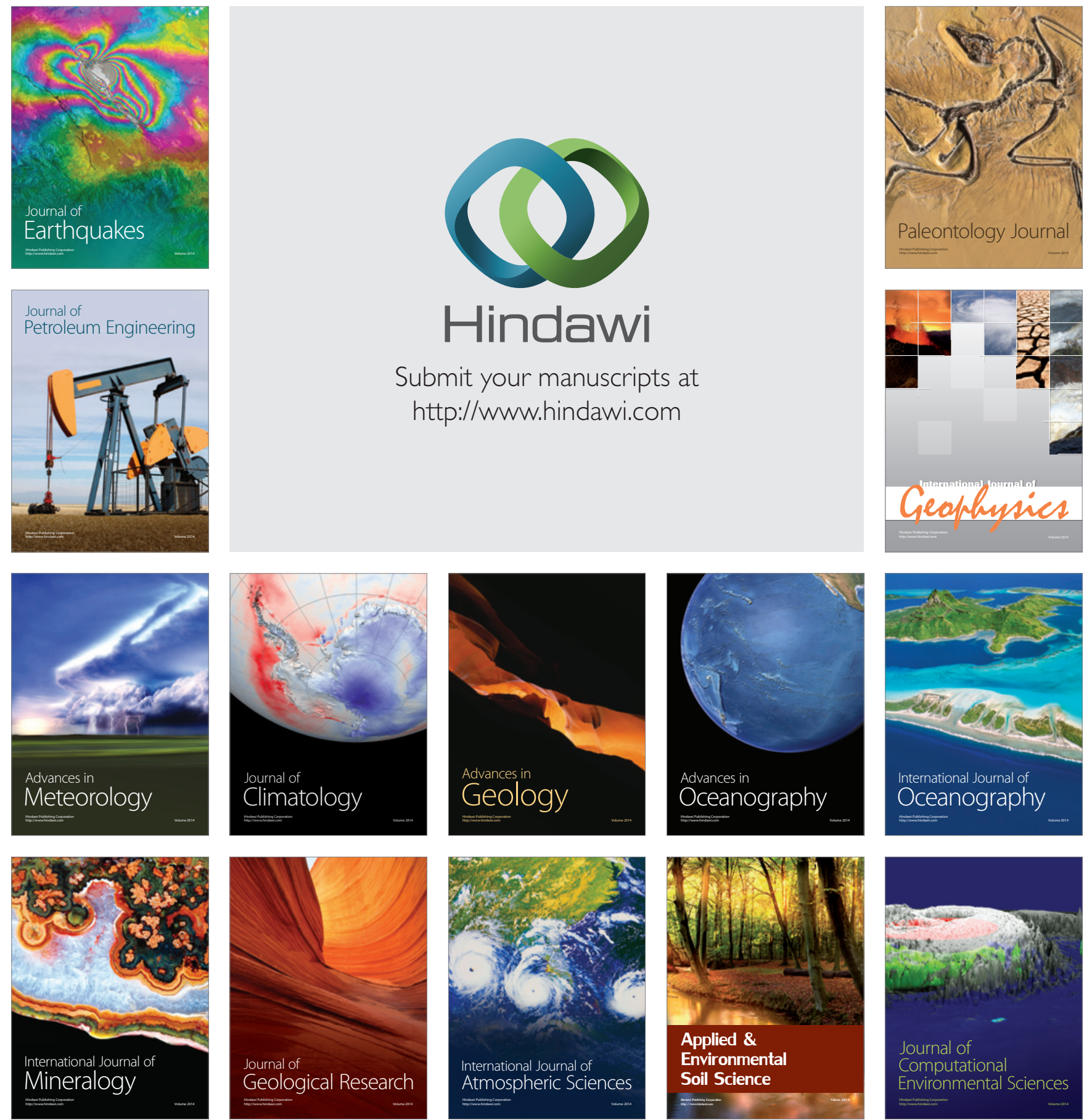